\title{
Determining the Dimension of Knowledge Management Implementation by Utilizing a Fuzzy TOPSIS Method
}

\author{
Mona Ahani (Corresponding author) \\ Faculty of management, Islamic Azad University, Naragh Branch, Naragh, Iran \\ Tel: 98-91-2746-9744Ｅ-mail: ahani.mona@yahoo.com \\ Hamid Reza Bahrami \\ Faculty of management, Islamic Azad University, Naragh Branch, Naragh, Iran \\ E-mail: drbahrami@yahoo.com \\ Behrooz Shariflu \\ Instructor at Shams Tabrizi, Higher Education Institute, Khoy, Iran \\ E-mail: behroozshariflu@yahoo.com
}

Received: November 20, 2012

Accepted: December 16, 2012 Online Published: January 5, 2013

doi:10.5430/ijba.v4n1p113

URL: http://dx.doi.org/10.5430/ijba.v4n1p113

\begin{abstract}
The purpose of this research is to identify and rank different aspects of knowledge management based on the Beckman model using the Fuzzy TOPSIS technique. The Beckman model, in this research, has 8 main dimensions including: knowledge identification, knowledge acquisition, knowledge selection, knowledge storage, knowledge distribution, knowledge creation, knowledge application, knowledge business, and 33 sub-criteria or alternatives. The population of the present study includes 197 members of the Education and Research Department staff of Islamic Azad University, Science and Research Branch. Using Chi 2 correlation tests at first, a positive and meaningful correlation between the 8 above-mentioned criteria and knowledge management implementation in this University Branch was confirmed. Then the components of the Beckman model were ranked using Fuzzy TOPSIS technique. Finally "high value and uniqueness of the available knowledge in the university" was selected as the most significant sub criterion of the Beckman model and "the amount of existing knowledge transforming into directions, strategies and guidelines" and "the amount of the existing documented knowledge in the university" were selected as the most effective factors in the knowledge management implementation. In addition, knowledge selection, knowledge storage and knowledge application were selected as the most important dimensions of knowledge management in the Beckman model.
\end{abstract}

Keywords: Knowledge management, Beckman model, Multi-Criteria Decision Making (MCDM), Fuzzy TOPSIS

\section{Introduction}

One way to succeed in implementing knowledge management is to present a definite and organized framework. This framework has an important role in the organization in order to be able to organize its sources and capacities to reach to the knowledge management aims and consequently to be able to help the organization in the important issue of marketing.

The most important role which can be given to knowledge management is to regard it as a transition methodology. By absorbing new knowledge into the system on the one hand and organizing this knowledge effectively on the other hand, knowledge management can be the most important transition factor in an organization (Hales, 2001).

Although knowledge management may look simple, organizations which try to transform into knowledge based organizations face fundamental problems for which there are no exact solutions. Furthermore, they don't have access to any particular guidelines to implement methods and concepts of knowledge management. 
So, before managers start implementing processes and methods of knowledge management in their own organizations, they have to choose the appropriate strategy for implementing knowledge management for their organization. Both scientific and commercial communities believe that organizations can keep their long term superiority in competitive arenas by utilizing the power of knowledge. So in this research, by testing the Beckman model, the most important dimensions of its implementation in Islamic Azad University, Science and Research branch are going to be identified and then by the TOPSIS fuzzy techniques, the sub criteria are going to be ranked. Finally with regard to the results, some recommendations are made towards implementing knowledge management.

\section{Literature Review}

\subsection{Knowledge}

In the heart of information technology, knowledge is separate from data and information. While data is a collection of facts and measures, information is organized or processed data which has an expiration date and of course high accuracy. Knowledge is the information which can have an impact on the action. Practicality means to be relevant to particular fields. For this purpose relevant information should be accessible in an appropriate place, time and context so that everybody can use it in making their decisions (Salvendy, 2001).

Knowledge is a key source in intelligent decision making, forecasting, planning, programming, troubleshooting and diagnosis, analysis, evaluation and intuitive judgment. Knowledge is formed and shared in the space between individual and collective minds (Tiwana, 2000).

Knowledge can be considered as a capacity. Meaning, knowledge does not do a particular action, but has the ability to interpret and use the information and experiences influencing the decisions (Watson, 1999).

\subsection{Knowledge Management}

Knowledge management is a process which helps organizations to identify, select, organize, and publish (transmit) information and important specialties. It is part of the organizational memory and often exists in an unstructured form in the organization (Turban and McLean, 2002). In another definition, knowledge management is defined as an awareness of the existing knowledge in the organization. It is also the creating, sharing and transferring of knowledge, employing the existing knowledge, and acquiring, storing and accumulating new knowledge. These measures are taken place in organizational learning with regard to the strategy and culture of the organization (Sallis and Jones, 2002).

Organizing and giving structure to knowledge improves effective and efficient problem solving, dynamic learning, strategic planning and effective decision making. Knowledge management focuses on knowledge identification, description, organization, and increasing its value through the possibility of reusing it. The concept of knowledge management has been applied in different fields like knowledge engineering (De Hoog, 1997) and artificial intelligence (Glazer, 1998).

Developments that have occurred in data processing and network technologies, have increased access to data and information via the internet. It may be accessed at anytime, anywhere in the world (Bokma, 2000). Malhotra (2000 \& 2001 ) is of the opinion that "knowledge management caters to the critical issues of organizational adaptation, survival, and competence in the face of increasingly discontinuous environmental change. Essentially, it embodies organizational processes that seek a synergistic combination of data and information processing capacity of information technologies, and the creative and innovative capacity of human beings" (Malhotra, 2000 \& 2001). Alavi and Leidner (1999) define knowledge management as "a systemic and organizationally specified process for acquiring, organizing, and communicating both tacit and explicit knowledge of employees so that other employees may make use of it to be more effective and productive in their work" (Alavi and Leidner, 1999).

\subsection{Beckman Model}

In 1999 Beckman proposed the following 8 stages for the knowledge management process:

1). Identification: Determining internal competencies, strategy resources, and the realm of knowledge.

2). Acquisition: Making the available existing knowledge official.

3). Selection: Determining the relationship between knowledge, value, and accuracy and eliminating incompatible knowledge.

4). Storage: Introducing the united memory in the knowledge repository with various knowledge patterns.

5). Distribution: Distributing knowledge for users automatically based on interest, use and collaboration among groups. 
6). Creation: Generating new knowledge through research, experience and creative thinking.

7). Application: Restoring and using knowledge in decision making, problem solving, supporting and making the tasks automatic, and helping jobs and training.

8). Business: Sales and trading, developing and marketing the new knowledge in the form of products and services.

\section{Research Methodology}

The present study can be considered an applied research in terms of the goal, and descriptive co-relational in terms of the method of gathering data, and since it studies a particular society it may be considered a case-study. For gathering data, library method (referring to the books, articles, records, internet ...) and field study (distribution of questionnaire) were used.

Two separate questionnaires were designed for identifying and ranking different aspects of knowledge management. Both questionnaires contain 33 identical questions. The first questionnaire used a 5 point Likert scale for identification of the aspects of knowledge management implementation, and the second one used the 7 point scale related to Fuzzy TOPSIS.

The results of the knowledge management implementation outputs are needed in order to rank these 33 mentioned criteria, which are regarded as the criteria for ranking scales of the sub-criteria. Then, by reviewing the literature, 11 different criteria were identified, and three of them were selected as the most important criteria including: "learning and empowerment", "Organization performance" and "Competitive advantage".

The population of the present study includes 401 participants from Education and Research Department staff as well as Education and Research units of 19 faculties of the Islamic Azad University, Science and Research Branch. Because of the great number of the population, sampling method with the following formula was used for determining the sample volume (Azar and Momeni, 2005, 76).

$$
n=\frac{N Z^{2}{ }_{1-\frac{a}{2}} p q}{(N-1) \varepsilon^{2}+Z_{1-\frac{a}{2}}^{2} p q} \Rightarrow \frac{401 \times(1.96)^{2} \times(0.5)^{2}}{400 \times(0.05)^{2}+(1.96)^{2}(0.5)^{2}} \cong 197
$$

Where

$\mathrm{P}$ : Estimation of the proportion of variable $(\mathrm{P}=0.5)$

$Z$ : The value of normal variable corresponding to confidence level of $95 \%\left(Z_{\alpha / 2}=1.96\right)$

$\varepsilon$ : The amount of allowable error $(\varepsilon=0.05)$

$\mathrm{N}$ : Finite population size (401people)

Therefore, the sample volume was decreased to 197. For determining the questionnaire validity, content validity of the questionnaire was measured. The questionnaires were distributed among the professors of distribution management, and after removing all flaws and ambiguities, they were distributed among statistical society.

In order to evaluate the reliability of the questionnaire by SPSS 16 statistical software, Cronbach's alpha reliability coefficient was calculated and the result was 0.82 which shows the high reliability of the questionnaire.

\subsection{Fuzzy TOPSIS Technique}

TOPSIS (technique of ranking by similarity by positive ideal solution), known as a classical multiple criteria decision-making (MCDM) method, was first developed by Hwang and Yoon (1981) for solving MCDM problems, which was based on determining the ideal solution. The selected alternative should have the shortest distance from the positive ideal solution and on the other side the farthest distance from the negative ideal solution (Hwang and Yoon, 1981).

Fuzzy TOPSIS technique in Iran started in the 1990s in a restricted form, and some instances of its application are limited to the recent years.

Decision making process steps by fuzzy TOPSIS technique are as follows:

Step 1: Calculating weights vector $\mathrm{w}_{\mathrm{j}}$

Step 2: Normalizing the matrix obtained from experts opinions regarding the alternatives, which forms a new matrix as the follows: 


$$
\widetilde{R}=\left[\widetilde{r}_{i j}\right]_{m \times n}
$$

$B \subseteq\{1, \ldots, n\}$ refers to the interest indices (2) and $C \subseteq\{1, \ldots, n\}$ refers to the cost indices (3).

$$
\begin{gathered}
\tilde{r}_{i j}=\left(\frac{a_{i j}}{d_{j}^{+}}, \frac{b_{i j}}{d_{j}^{+}}, \frac{c_{i j}}{d_{j}^{+}}, \frac{d_{i j}}{d_{j}^{+}}\right), \quad j \in B \\
d_{j}^{+}=\max _{i} d_{i j} \text { if } j \in B \\
\tilde{r}_{i j}=\left(\frac{a_{j}^{-}}{d_{i j}}, \frac{a_{j}^{-}}{c_{i j}}, \frac{a_{j}^{-}}{b_{i j}}, \frac{a_{j}^{-}}{a_{i j}}\right), \quad j \in C \\
a_{j}^{-}=\min _{i} a_{i j} \quad \text { if } j \in C
\end{gathered}
$$

Step 3: So normalized weighted matrix is calculated as formula 4:

$$
\begin{gathered}
\tilde{V}=\left[\tilde{v_{i j}}\right]_{m \times n}, \quad i=1,2, \ldots, m, j=1,2, \ldots, n \\
\tilde{v}_{i j}=\tilde{r}_{i j} \otimes \tilde{w}_{j}
\end{gathered}
$$

Step 4: Determining the fuzzy positive ideal solution $(F P I S)^{\widetilde{V}_{j}^{*}}$ and fuzzy negative ideal solution $(F N I S)^{\widetilde{V}_{j}^{-}}$ (Formulas 5 and 6):

$$
\begin{gathered}
\tilde{v}_{j}^{+}=\left\{\begin{array}{l}
\max _{i=1 \ldots, m} \quad \tilde{v}_{i j} ; j \in B \\
\min \quad \tilde{v}_{i j} ; j \in C \\
\text { FPIS }=\left\{\tilde{v}_{j}^{+} \mid j=1, \ldots, n\right\}
\end{array}\right. \\
\tilde{v}_{j}^{-}=\left\{\begin{array}{l}
\min _{i=1 \ldots, m} \\
\max \\
\max _{i=1 \ldots, m}
\end{array} \quad \tilde{v}_{i j} ; j \in C\right. \\
F N I S=\left\{\tilde{v}_{j}^{-} \mid j=1, \ldots, n\right\}
\end{gathered}
$$

Step 5: Calculating the distances using Fuzzy Euclidian distance:

$$
D(\tilde{a}, \tilde{b})=\sqrt{\frac{1}{4}\left[\left(a_{1}-b_{1}\right)^{2}+\left(a_{2}-b_{2}\right)^{2}+\left(a_{3}-b_{3}\right)^{2}+\left(a_{4}-b_{4}\right)^{2}\right]}
$$

The distance of each alternative from positive and negative ideal is calculated by applying formulas 8 and 9: 


$$
\begin{aligned}
& S_{i}^{+}=\sum_{j=1}^{n} D\left(\tilde{v_{i j}}, v_{j}^{+}\right), \quad i=1,2, \ldots, m, \\
& S_{i}^{-}=\sum_{j=1}^{n} D\left(\tilde{v}_{i j}, v_{j}^{-}\right), \quad i=1,2, \ldots, m,
\end{aligned}
$$

Step 6: Calculating the relative closeness to the ideal solution and ranking (10):

$$
C c_{i}=\frac{S_{i}^{-}}{S_{i}^{+}+S_{i}^{-}}, \quad i=1,2, \ldots, m
$$

\section{Data Analysis}

\subsection{The Results of Applying the Chi 2 Test}

To identify the relationship between the dimensions of knowledge management model and the implementation of knowledge management based on Beckman model at the Islamic Azad University, Science and Research Branch, Karl Pearson's Chi 2 test was applied. The results of applying this test are shown in Table 1.

As it is shown in Table 1, the sig degree for all variables is lower than research error degree (0.05), so, it is approved that there is a positive and meaningful correlation between knowledge identification, knowledge acquisition, knowledge selection, Knowledge saving, Knowledge distribution, knowledge creation, Knowledge application and knowledge business and knowledge management implementation.

\subsection{Setting Priority of Beckman Model Elements Using Fuzzy TOPSIS Technique}

In real-word situations, because of incomplete or non-accessible information, the data (attributes) are often not so definitive; rather they usually are fuzzy/ imprecise. So, we try to extend TOPSIS for fuzzy data to set a priority of the elements of knowledge management implementation. The fuzzy degrees of linguistic variables for determining the weight of each criterion are shown in Table 2. (Chen, 2000).

The fuzzy decision making matrix and fuzzy weights for the elements of knowledge management implementation obtained by using the opinions of managers and specialists are calculated as follows: (see Table 3 ).

The fuzzy weighted normalized matrix is also shown in Table 4. It should be mentioned that due to the high amount of calculations, fuzzy weighted normalized matrix is not mentioned here.

At the third step of decision making, fuzzy weighted normalized matrix was obtained (Table 4). It should be mentioned that due to the high amounts of calculations, fuzzy weighted normalized matrixes obtained from formulas 2 and 3 are not mentioned here. Table 4 was created using formula 4.

At the next step, the total number of positive and negative ideal points will be obtained by using formulas 8 and 9 . The positive ideal points show the distance from positive ideal, and negative ideal points show the distance from negative ideal. Therefore, the less the distance from positive ideal points and the more the distance from negative ideal points, the higher the priority of indices. The closeness coefficient obtained from formula 10 , indicates the degree of indices' importance, that is the more the closeness coefficient, the higher the priority of the variables.

The total number of positive and negative ideal points, closeness coefficient and the final ranking are also shown in Table 5.

With regard to Table 5 "high value and uniqueness of the available knowledge in the university" was selected as the most significant sub-criterion of Beckman model and "the amount of transforming the existing knowledge into directions, strategies and guidelines" and "the amount of the existing documented knowledge in the university" were selected as the second and the third sub-criteria. In Beckman model knowledge selection (0.601181), knowledge storage (0.574359) and knowledge application (0.569222) were selected as the most important criteria.

\section{Conclusion and Recommendations}

The purpose of the present research is to determining the dimension of knowledge management iImplementation by utilizing a fuzzy TOPSIS method based on the Beckman model at the Islamic Azad University, Science and Research Branch.

The population of the present study includes 197 members of the Education and Research Department staff of Islamic Azad University, Science and Research Branch. Fourty-four percent of the participants were women and 
$56 \%$ were men. Sixteen percent were $20-30$ years old, $47 \%$ were $31-40$ years old, and the remaining $37 \%$ were above 40 years old. Moreover, $86 \%$ had a B.A degree or were under graduated and $14 \%$ had a M.A. degree. In addition, $9 \%$ of the participants had less than 5 years of work experience, $81 \%$ had $6-15$ years of work experience, and $10 \%$ had 16-25 years of work experience.

The Beckman model consists of 8 main dimensions including; knowledge identification, knowledge acquisition, knowledge selection, knowledge storage, knowledge distribution, knowledge creation, knowledge application, and knowledge business.

At first, a positive and meaningful correlation between the above-mentioned aspects and knowledge management implementation at Islamic Azad University, Science and Research Branch was approved, by the application of a Chi 2 test.

Finally, by using the fuzzy TOPSIS technique, the components of the Beckman model were ranked accordingly: "high value and uniqueness of the available knowledge in the university" factor was selected as the most significant sub criterion of Beckman model, and "the amount of transforming the existing knowledge into directions, strategies and guidelines" and "the amount of the existing documented knowledge in the university" were selected as the most effective factors in the knowledge management implementation. In addition knowledge selection, knowledge storage and knowledge application were selected as the most important main dimensions of knowledge management in the Beckman model.

Considering the results of the present study, the following recommendations may be given:

There is a positive and direct correlation between knowledge identification and knowledge management implementation. Therefore, investigation of the staff's situation by the managers and identifying their strong and weak points can improve the organization's knowledge quality. Managers can also improve by trying to identify existing issues and problems in the organization.

There is a direct and positive correlation between knowledge acquisition and knowledge management implementation. In this regard, documentation of the existing knowledge in the organization can help knowledge acquisition significantly. Employing ideas, skills, expertise, educations and experiences of the staff for implementing strategies, technologies, processes, methods, etc. can be useful and effective means to improve knowledge acquisition in Islamic Azad University, Science and Research Branch.

There is a direct and positive correlation between knowledge selection and knowledge management implementation. Modifying the knowledge which is easily accessible and can be copied by competitors into an implicit one can be one way to improve the knowledge selection process. Investing in the issues which are crucial for the university based on the managers' opinions can also be another way to improve the knowledge selection process.

There is a positive and direct correlation between knowledge storage and knowledge management implementation. The following recommendations may be given for storing the knowledge and preventing its destruction, including documentation of all the available projects and experiences, and preventing managerial changes and substitutions which will have considerable negative impacts on the organization.

There is a direct and positive correlation between knowledge distribution and management implementation. Therefore, it can be recommended to the university managers that they hold meetings in which people can share their ideas and opinions, benefit from the knowledge and experience of each other, and have great contributions in knowledge sharing and transfer.

There is a positive and direct correlation between knowledge creation and knowledge management implementation. Therefore, in order to create and produce a higher level of organizational knowledge, the following solutions may be addressed including: to let the staff present new ideas, to provide opportunities for the staff to participate in the decision making processes and organizational meetings held periodically, and to employ and use people who are seeking higher levels of knowledge and learning.

There is a positive and direct correlation between knowledge application and knowledge management implementation. The application of available documents obtained from earlier projects in the organization and providing all people with the possibility to have access to the organizational information and documents can help to increase knowledge application in this branch.

There is a direct and positive correlation between knowledge business and knowledge management implementation. In this regard, there are some guidelines including better relationships with students and the staff, employing specialists and experienced people in marketing and advertising processes to attract students and give services, 
convening periodical meetings to investigate and analyze competitors' conditions and needed investments for more advertising and marketing. They will result in the improvement of knowledge business.

\section{References}

Alavi, M., \& Leidner, D. (1999). Knowledge Management System: Issues, Challenges and Benefits. Communications of the Association for Information System, 1(7), 2-41.

Azar, Adel, \& Momeni, Mansour. (2005). Statistics and Its Application in Management (Volume II, 8th ed.). Tehran: Samt Press.

Beckman, T. (1999). The Current State Of knowledge management. In Libuwitz (ed.), The knowledge Management Hand Book, Boca Raton. CRC. Press.

Bekman, T. (1999). The Current State Of knowledge management. In Libuwitz (ed.), The knowledge Management Field Book. Financial Times Prentice Hall, London.

Bokma, A. (2000). Integrated information and knowledge management and its use in virtual organizations. E-business and virtual enterprises (2nd ed.). IFIP.

Chen, C.T. (2000). Extension of The TOPSIS for Group Decision- making under Fuzzy Environment. Fuzzy Sets and Systems, (114), 1-9.

De Hoog, R. (1997). Common KADS: knowledge acquisition and design support methodology for structuring the KBS integration process. In Knowledge management and integratives elements. CRC.press, Bocaraton, FL.

Glazer, R. (1998). Measuring the knower: towrd a theory of knowledge equity. California management review, 40(3).

Hales, Steve (2001). Dimension knowledge and its management. [Online] Available: www.insighting.co.uk

Malhotra, Y. (2000). Knowledge Assets in the Global Economy: Assessment of National Intellectual Capital. Journal of Global Information Management, 8(3), 5-15.

Malhotra, Y. (2001). Knowledge Management and Business Model Innovation, Idea Group Publishing, London.

Sallis, E., \& Jones, G. (2002). Knowledge management in Education. Great Britation: Kogan Press.

Salvendy, G. (2001). Computer integrated technologies and knowledge management. In Hand book of industrial engineering: technology and operations management ( $23^{\text {rd }}$ ed., pp.177-223). John wiley \& sons, Inc.

Tiwana, A. (2000). The knowledge management tool kit. Prentice - Hall, Upper sadde river, NJ.

Turban, E., \& Mclean, E. (2002). Information technology for management (3rd ed.). John wiley \& Sons.Inc.

Watson, R.T. (1999). Data management: databases and organizations $\left(2^{\text {nd }}\right.$ ed.). John wiley, New York.

Table 1. Results obtained from using Chi2 test

\begin{tabular}{|c|c|c|c|}
\hline variables & sig & Chi 2 & Test result \\
\hline $\begin{array}{c}\text { Knowledge } \\
\text { identification }\end{array}$ & 0.017 & 6.429 & Positive and meaningful correlation \\
\hline Knowledge acquisition & 0.037 & 12.223 & Positive and meaningful correlation \\
\hline Knowledge selection & 0.029 & 7.381 & Positive and meaningful correlation \\
\hline Knowledge saving & 0.012 & 8.425 & Positive and meaningful correlation \\
\hline Knowledge distribution & 0.019 & 9.012 & Positive and meaningful correlation \\
\hline Knowledge creation & 0.021 & 9.531 & Positive and meaningful correlation \\
\hline Knowledge application & 0.022 & 7.625 & Positive and meaningful correlation \\
\hline Knowledge business & 0.015 & 8.798 & Positive and meaningful correlation \\
\hline
\end{tabular}


Table 2. Linguistic variables for determining the weight of each criterion

\begin{tabular}{|c|c|c|}
\hline Very Low & VL & $(0.0 .1 .2)$ \\
\hline Low & $\mathrm{L}$ & $(1.2 .2 .3)$ \\
\hline Medium Low & $\mathrm{ML}$ & $(2.3 .4 .5)$ \\
\hline Medium & $\mathrm{M}$ & $(4.5 .5 .6)$ \\
\hline Medium High & $\mathrm{MH}$ & $(5.6 .7 .8)$ \\
\hline High & $\mathrm{H}$ & $(7.8 .8 .9)$ \\
\hline Very High & $\mathrm{VH}$ & $(8.9 .10 .10)$ \\
\hline
\end{tabular}

Table 3. Fuzzy decision making matrix and fuzzy weights

\begin{tabular}{|c|c|c|c|c|c|c|c|c|c|c|c|c|}
\hline \multirow{3}{*}{$\begin{array}{c}\text { Variables } \\
\text { P1 }\end{array}$} & 8 & 9 & 10 & 10 & 5 & 6 & 7 & 8 & 7 & 8 & 8 & 9 \\
\hline & \multicolumn{4}{|c|}{$\begin{array}{l}\text { Learning and } \\
\text { Empowerment }\end{array}$} & \multicolumn{4}{|c|}{ Performance } & \multicolumn{4}{|c|}{ Competitive Advantage } \\
\hline & 7 & 8 & 8 & 9 & 7 & 8 & 8 & 9 & 8 & 9 & 10 & 10 \\
\hline $\mathrm{P} 2$ & 2 & 3 & 4 & 5 & 5 & 6 & 7 & 8 & 2 & 3 & 4 & 5 \\
\hline P3 & 8 & 9 & 10 & 10 & 2 & 3 & 4 & 5 & 5 & 6 & 7 & 8 \\
\hline P4 & 7 & 8 & 8 & 9 & 7 & 8 & 8 & 9 & 4 & 5 & 5 & 6 \\
\hline P5 & 7 & 8 & 8 & 9 & 7 & 8 & 8 & 9 & 1 & 2 & 2 & 3 \\
\hline P6 & 8 & 9 & 10 & 10 & 2 & 3 & 4 & 5 & 7 & 8 & 8 & 9 \\
\hline P7 & 8 & 9 & 10 & 10 & 4 & 5 & 5 & 6 & 7 & 8 & 8 & 9 \\
\hline P8 & 4 & 5 & 5 & 6 & 4 & 5 & 5 & 6 & 7 & 8 & 8 & 9 \\
\hline P9 & 2 & 3 & 4 & 5 & 2 & 3 & 4 & 5 & 8 & 9 & 10 & 10 \\
\hline P10 & 8 & 9 & 10 & 10 & 0 & 0 & 1 & 2 & 2 & 3 & 4 & 5 \\
\hline P11 & 8 & 9 & 10 & 10 & 7 & 8 & 8 & 9 & 2 & 3 & 4 & 5 \\
\hline P12 & 7 & 8 & 8 & 9 & 5 & 6 & 7 & 8 & 7 & 8 & 8 & 9 \\
\hline P13 & 2 & 3 & 4 & 5 & 4 & 5 & 5 & 6 & 7 & 8 & 8 & 9 \\
\hline P14 & 7 & 8 & 8 & 9 & 2 & 3 & 4 & 5 & 8 & 9 & 10 & 10 \\
\hline P15 & 1 & 2 & 2 & 3 & 8 & 9 & 10 & 10 & 4 & 5 & 5 & 6 \\
\hline P16 & 8 & 9 & 10 & 10 & 8 & 9 & 10 & 10 & 2 & 3 & 4 & 5 \\
\hline P17 & 2 & 3 & 4 & 5 & 8 & 9 & 10 & 10 & 4 & 5 & 5 & 6 \\
\hline P18 & 4 & 5 & 5 & 6 & 8 & 9 & 10 & 10 & 2 & 3 & 4 & 5 \\
\hline P19 & 7 & 8 & 8 & 9 & 0 & 0 & 1 & 2 & 2 & 3 & 4 & 5 \\
\hline P20 & 2 & 3 & 4 & 5 & 4 & 5 & 5 & 6 & 0 & 0 & 1 & 2 \\
\hline P21 & 2 & 3 & 4 & 5 & 6 & 7 & 7 & 8 & 4 & 5 & 5 & 6 \\
\hline $\mathrm{P} 22$ & 0 & 0 & 1 & 2 & 2 & 3 & 4 & 5 & 7 & 8 & 8 & 9 \\
\hline $\mathrm{P} 23$ & 4 & 5 & 5 & 6 & 4 & 5 & 5 & 6 & 5 & 6 & 7 & 8 \\
\hline P24 & 0 & 0 & 1 & 2 & 5 & 6 & 7 & 8 & 0 & 0 & 1 & 2 \\
\hline P25 & 2 & 3 & 4 & 5 & 7 & 8 & 8 & 9 & 4 & 5 & 5 & 6 \\
\hline
\end{tabular}




\begin{tabular}{|c|c|c|c|c|c|c|c|c|c|c|c|c|}
\hline P26 & 4 & 5 & 5 & 6 & 7 & 8 & 8 & 9 & 7 & 8 & 8 & 9 \\
\hline P27 & 2 & 3 & 4 & 5 & 8 & 9 & 10 & 10 & 7 & 8 & 8 & 9 \\
\hline P28 & 8 & 9 & 10 & 10 & 2 & 3 & 4 & 5 & 0 & 0 & 1 & 2 \\
\hline P29 & 4 & 5 & 5 & 6 & 8 & 9 & 10 & 10 & 7 & 8 & 8 & 9 \\
\hline P30 & 2 & 3 & 4 & 5 & 4 & 5 & 5 & 6 & 8 & 9 & 10 & 10 \\
\hline P31 & 5 & 6 & 7 & 8 & 2 & 3 & 4 & 5 & 5 & 6 & 7 & 8 \\
\hline P32 & 4 & 5 & 5 & 6 & 7 & 8 & 8 & 9 & 0 & 0 & 1 & 2 \\
\hline P33 & 4 & 5 & 5 & 6 & 7 & 8 & 8 & 9 & 5 & 6 & 7 & 8 \\
\hline
\end{tabular}

Table 4. Fuzzy weighted normalized matrix

\begin{tabular}{|c|c|c|c|c|c|c|c|c|c|c|c|c|}
\hline Variables & \multicolumn{3}{|c|}{ Learning and } & \multicolumn{3}{c|}{ Performance } & \multicolumn{3}{c|}{ Competitive Advantage } \\
\hline P1 & 0.56 & 0.72 & 0.8 & 0.9 & 0.35 & 0.48 & 0.56 & 0.72 & 0.56 & 0.72 & 0.8 & 0.9 \\
\hline P2 & 0.16 & 0.27 & 0.4 & 0.5 & 0.25 & 0.36 & 0.49 & 0.64 & 0.14 & 0.24 & 0.32 & 0.45 \\
\hline P3 & 0.64 & 0.81 & 1 & 1 & 0.1 & 0.18 & 0.28 & 0.4 & 0.35 & 0.48 & 0.56 & 0.72 \\
\hline P4 & 0.56 & 0.72 & 0.8 & 0.9 & 0.35 & 0.48 & 0.56 & 0.72 & 0.28 & 0.4 & 0.4 & 0.54 \\
\hline P5 & 0.56 & 0.72 & 0.8 & 0.9 & 0.35 & 0.48 & 0.56 & 0.72 & 0.07 & 0.16 & 0.16 & 0.27 \\
\hline P6 & 0.64 & 0.81 & 1 & 1 & 0.1 & 0.18 & 0.28 & 0.4 & 0.49 & 0.64 & 0.64 & 0.81 \\
\hline P7 & 0.64 & 0.81 & 1 & 1 & 0.2 & 0.3 & 0.35 & 0.48 & 0.49 & 0.64 & 0.64 & 0.81 \\
\hline P8 & 0.32 & 0.45 & 0.5 & 0.6 & 0.2 & 0.3 & 0.35 & 0.48 & 0.49 & 0.64 & 0.64 & 0.81 \\
\hline P9 & 0.16 & 0.27 & 0.4 & 0.5 & 0.1 & 0.18 & 0.28 & 0.4 & 0.56 & 0.72 & 0.8 & 0.9 \\
\hline P10 & 0.64 & 0.81 & 1 & 1 & 0 & 0 & 0.07 & 0.16 & 0.14 & 0.24 & 0.32 & 0.45 \\
\hline P11 & 0.64 & 0.81 & 1 & 1 & 0.35 & 0.48 & 0.56 & 0.72 & 0.14 & 0.24 & 0.32 & 0.45 \\
\hline P12 & 0.56 & 0.72 & 0.8 & 0.9 & 0.25 & 0.36 & 0.49 & 0.64 & 0.49 & 0.64 & 0.64 & 0.81 \\
\hline P13 & 0.16 & 0.27 & 0.4 & 0.5 & 0.2 & 0.3 & 0.35 & 0.48 & 0.49 & 0.64 & 0.64 & 0.81 \\
\hline P14 & 0.56 & 0.72 & 0.8 & 0.9 & 0.1 & 0.18 & 0.28 & 0.4 & 0.56 & 0.72 & 0.8 & 0.9 \\
\hline P15 & 0.08 & 0.18 & 0.2 & 0.3 & 0.4 & 0.54 & 0.7 & 0.8 & 0.28 & 0.4 & 0.4 & 0.54 \\
\hline P16 & 0.64 & 0.81 & 1 & 1 & 0.4 & 0.54 & 0.7 & 0.8 & 0.14 & 0.24 & 0.32 & 0.45 \\
\hline P17 & 0.16 & 0.27 & 0.4 & 0.5 & 0.4 & 0.54 & 0.7 & 0.8 & 0.28 & 0.4 & 0.4 & 0.54 \\
\hline P18 & 0.32 & 0.45 & 0.5 & 0.6 & 0.4 & 0.54 & 0.7 & 0.8 & 0.14 & 0.24 & 0.32 & 0.45 \\
\hline P19 & 0.56 & 0.72 & 0.8 & 0.9 & 0 & 0 & 0.07 & 0.16 & 0.14 & 0.24 & 0.32 & 0.45 \\
\hline P20 & 0.16 & 0.27 & 0.4 & 0.5 & 0.2 & 0.3 & 0.35 & 0.48 & 0 & 0 & 0.08 & 0.18 \\
\hline P21 & 0.16 & 0.27 & 0.4 & 0.5 & 0.3 & 0.42 & 0.49 & 0.64 & 0.28 & 0.4 & 0.4 & 0.54 \\
\hline P22 & 0 & 0 & 0.1 & 0.2 & 0.1 & 0.18 & 0.28 & 0.4 & 0.49 & 0.64 & 0.64 & 0.81 \\
\hline P23 & 0.32 & 0.45 & 0.5 & 0.6 & 0.2 & 0.3 & 0.35 & 0.48 & 0.35 & 0.48 & 0.56 & 0.72 \\
\hline P24 & 0 & 0 & 0.1 & 0.2 & 0.25 & 0.36 & 0.49 & 0.64 & 0 & 0 & 0.08 & 0.18 \\
\hline P25 & 0.16 & 0.27 & 0.4 & 0.5 & 0.35 & 0.48 & 0.56 & 0.72 & 0.28 & 0.4 & 0.4 & 0.54 \\
\hline P26 & 0.32 & 0.45 & 0.5 & 0.6 & 0.35 & 0.48 & 0.56 & 0.72 & 0.49 & 0.64 & 0.64 & 0.81 \\
\hline
\end{tabular}




\begin{tabular}{|c|c|c|c|c|c|c|c|c|c|c|c|c|}
\hline P27 & 0.16 & 0.27 & 0.4 & 0.5 & 0.4 & 0.54 & 0.7 & 0.8 & 0.49 & 0.64 & 0.64 & 0.81 \\
\hline P28 & 0.64 & 0.81 & 1 & 1 & 0.1 & 0.18 & 0.28 & 0.4 & 0 & 0 & 0.08 & 0.18 \\
\hline P29 & 0.32 & 0.45 & 0.5 & 0.6 & 0.4 & 0.54 & 0.7 & 0.8 & 0.49 & 0.64 & 0.64 & 0.81 \\
\hline P30 & 0.16 & 0.27 & 0.4 & 0.5 & 0.2 & 0.3 & 0.35 & 0.48 & 0.56 & 0.72 & 0.8 & 0.9 \\
\hline P31 & 0.4 & 0.54 & 0.7 & 0.8 & 0.1 & 0.18 & 0.28 & 0.4 & 0.35 & 0.48 & 0.56 & 0.72 \\
\hline P32 & 0.32 & 0.45 & 0.5 & 0.6 & 0.35 & 0.48 & 0.56 & 0.72 & 0 & 0 & 0.08 & 0.18 \\
\hline P33 & 0.32 & 0.45 & 0.5 & 0.6 & 0.35 & 0.48 & 0.56 & 0.72 & 0.35 & 0.48 & 0.56 & 0.72 \\
\hline
\end{tabular}

Table 5. Total number of positive and negative ideal points and indices' final weights

\begin{tabular}{|c|c|c|c|c|}
\hline Indices & $\mathbf{D}^{+}{ }_{\mathrm{i}}$ & $\mathbf{D}_{\mathrm{i}}^{-}$ & $\mathbf{C l}_{\mathbf{i}}$ & Rank \\
\hline $\begin{array}{l}\text { The need for previous experience to solve } \\
\text { problems }\end{array}$ & 1.434417135 & 2.054894568 & 0.58891115 & 4 \\
\hline The rate of repetitive problems rate & 1.984752883 & 1.124365416 & 0.361634813 & 30 \\
\hline $\begin{array}{l}\text { Managers' awareness of the problems in } \\
\text { your unit and other projects }\end{array}$ & 1.462922695 & 1.68467541 & 0.535225703 & 11 \\
\hline $\begin{array}{c}\text { Managers' rate of awareness of } \\
\text { capabilities and abilities of their personnel } \\
\text { for referral }\end{array}$ & 1.376951566 & 1.714911257 & 0.554653086 & 8 \\
\hline $\begin{array}{l}\text { The rate of employing professional and } \\
\text { skilled staff in knowledge management }\end{array}$ & 1.612875417 & 1.479162914 & 0.478377936 & 15 \\
\hline $\begin{array}{l}\text { The rate of available knowledge in the } \\
\text { university in documented form }\end{array}$ & 1.344401895 & 1.795276248 & 0.571802639 & 3 \\
\hline $\begin{array}{c}\text { The rate of transformation of the available } \\
\text { knowledge in the university into } \\
\text { guidelines, strategies, and methods }\end{array}$ & 1.251231212 & 1.877778455 & 0.600119097 & 2 \\
\hline $\begin{array}{l}\text { The rate of universities' investment to } \\
\text { employ professionals in the field of } \\
\text { knowledge documentation }\end{array}$ & 1.589663909 & 1.480573457 & 0.482234199 & 14 \\
\hline $\begin{array}{c}\text { Picking and assessing technical, } \\
\text { qualitative, and financial characteristics of } \\
\text { the advisors for performing practical } \\
\text { projects }\end{array}$ & 1.731767736 & 1.37681326 & 0.442907314 & 21 \\
\hline $\begin{array}{l}\text { Convening some meetings to remove or } \\
\text { modify the content of documented } \\
\text { knowledge which can easily be copied by } \\
\text { competitors }\end{array}$ & 1.869793846 & 1.271849459 & 0.404835729 & 26 \\
\hline $\begin{array}{l}\text { Connecting the available knowledge in the } \\
\text { university with administrative processes }\end{array}$ & 1.416152127 & 1.728793773 & 0.549705409 & 9 \\
\hline $\begin{array}{l}\text { High value and uniqueness of the } \\
\text { available knowledge in the university }\end{array}$ & 1.239831971 & 1.8689292 & 0.601181338 & 1 \\
\hline Performance of group activities & 1.727497652 & 1.358867361 & 0.440280834 & 22 \\
\hline $\begin{array}{l}\text { Providing the possibility of knowledge } \\
\text { and experience documentation of different } \\
\text { people (into the lessons acquired during } \\
\text { projects) }\end{array}$ & 1.335695191 & 1.775581834 & 0.570692298 & 6 \\
\hline $\begin{array}{l}\text { Disorder in performance of duties, } \\
\text { responsibilities and suspension of plans } \\
\text { due to managerial changes and }\end{array}$ & 1.834644281 & 1.249565976 & 0.405149413 & 25 \\
\hline
\end{tabular}




\begin{tabular}{|c|c|c|c|c|}
\hline substitutions & & & & \\
\hline Documentation of results by the staff & 1.343813341 & 1.81333661 & 0.574358722 & 5 \\
\hline $\begin{array}{l}\text { Providing opportunities for exchanging } \\
\text { ideas among university staff }\end{array}$ & 1.700685325 & 1.40068552 & 0.451634322 & 19 \\
\hline $\begin{array}{l}\text { Developing the culture of sharing the } \\
\text { knowledge and ideas among staff }\end{array}$ & 1.682246038 & 1.416131612 & 0.457055844 & 18 \\
\hline $\begin{array}{c}\text { Creating atmosphere of interest among the } \\
\text { university specialists for answering the } \\
\text { questions }\end{array}$ & 1.949987741 & 1.151706939 & 0.37131538 & 28 \\
\hline $\begin{array}{l}\text { Holding discussion and debate meetings } \\
\text { on business issues }\end{array}$ & 2.292795072 & 0.802489541 & 0.259261955 & 32 \\
\hline $\begin{array}{l}\text { Interest of the experienced people of the } \\
\text { organization to guide beginners }\end{array}$ & 1.833262114 & 1.250442688 & 0.405500127 & 24 \\
\hline $\begin{array}{l}\text { Access to useful information and scientific } \\
\text { and technical documents in time of need }\end{array}$ & 2.069579351 & 1.031622623 & 0.332652511 & 31 \\
\hline $\begin{array}{l}\text { Need for new and updated information } \\
\text { and knowledge }\end{array}$ & 1.708184709 & 1.369972619 & 0.445062573 & 20 \\
\hline $\begin{array}{c}\text { The staff resistance against the application } \\
\text { of new methods and knowledge }\end{array}$ & 2.450112953 & 0.669040274 & 0.214494199 & 33 \\
\hline $\begin{array}{l}\text { Using the earlier projects' experiences in } \\
\text { the undertaking projects }\end{array}$ & 1.773024111 & 1.316142683 & 0.426051026 & 23 \\
\hline The rate of new products or services & 1.405736456 & 1.677383984 & 0.544053992 & 10 \\
\hline $\begin{array}{l}\text { The rate of available skilled people in } \\
\text { marketing, attracting students and services } \\
\text { (such as workshops, seminars and } \\
\text { conferences) }\end{array}$ & 1.471231414 & 1.640220725 & 0.52715602 & 12 \\
\hline $\begin{array}{l}\text { The rate of buying knowledge from } \\
\text { experts or other reputable companies }\end{array}$ & 1.909699315 & 1.238898428 & 0.393476248 & 27 \\
\hline $\begin{array}{l}\text { The rate of analysis of information about } \\
\text { competitors, partners or students. }\end{array}$ & 1.33339767 & 1.761926821 & 0.569222008 & 7 \\
\hline The rate of new products or services & 1.638597053 & 1.459315467 & 0.47106413 & 16 \\
\hline $\begin{array}{c}\text { The rate of available skilled people in } \\
\text { marketing, attracting students and services } \\
\text { (such as workshops, seminars and } \\
\text { conferences) }\end{array}$ & 1.678199202 & 1.438026783 & 0.461464217 & 17 \\
\hline $\begin{array}{l}\text { The rate of buying knowledge from } \\
\text { experts or other reputable companies }\end{array}$ & 1.971033876 & 1.121006164 & 0.362545811 & 29 \\
\hline $\begin{array}{l}\text { The rate of analysis of information about } \\
\text { competitors, partners or students }\end{array}$ & 1.524257256 & 1.566783146 & 0.506878896 & 13 \\
\hline
\end{tabular}

(Source: research outputs) 